\title{
Musculomucosal Flap: A Technique for Correction of Velopharyngeal Insufficiency by Palate Lengthening
}

\author{
${ }^{1}$ Mazin M Deshmukh, ${ }^{2}$ Gaurav Deshpande
}

\begin{abstract}
A small but significant percentage of patients have inadequate velopharyngeal closure, or secondary velopharyngeal incompetence, following primary palatoplasty. The use of the buccinator musculomucosal (MM) flap has been described for both primary palate repair with lengthening and secondary palate lengthening for the correction of insufficient velopharyngeal closure. The MM flap was first described in 1969 for the primary repair of a wide cleft palate by Mukherji, and it was Bozola et al in 1989 who first formally described it and gave first description of its anatomy. The first report on its use to lengthen the palate in secondary velopharyngeal insufficiency (VPI) was published by Hill et al in 1999. This case report presents a patient who had correction of secondary velopharyngeal incompetence using bilateral buccinator MM flaps used as a sandwich and also gives a brief review of the literature regarding its application in cases of secondary VPI.
\end{abstract}

Keywords: Buccinator musculomucosal flap, Cleft palate, Velopharyngeal insufficiency.

How to cite this article: Deshmukh MM, Deshpande G. Musculomucosal Flap: A Technique for Correction of Velopharyngeal Insufficiency by Palate Lengthening. J Contemp Dent 2017;7(3):174-177.

Source of support: Nil

Conflict of interest: None

\section{INTRODUCTION}

Persistent inadequacy of velopharyngeal closure occurs in a small but significant percentage of patients following primary palate repair. ${ }^{1,2}$ Treatment of patients with consistent hypernasality, nasal airflow errors, passive cleft speech characteristics, and/or nasal regurgitation is usually surgical. ${ }^{3}$ A large number of surgical techniques are described to address VPI. These can be grossly divided into two categories: Palatoplasties, which are aimed at increasing the length and/or the mobility of the palate, and pharyngoplasties, which are aimed at

\footnotetext{
${ }^{1}$ Postgraduate Student, ${ }^{2}$ Lecturer

${ }^{1,2}$ Department of Oral and Maxillofacial Surgery, Mahatma Gandhi Mission's Dental College and Hospital, Navi Mumbai Maharashtra, India

Corresponding Author: Mazin M Deshmukh, Postgraduate Student, Department of Oral and Maxillofacial Surgery Mahatma Gandhi Mission's Dental College and Hospital, Navi Mumbai, Maharashtra, India, Phone: +917741931033, e-mail: mazinmasoom@gmail.com
}

decreasing the velopharyngeal space. ${ }^{4}$ The inability to achieve sufficient velopharyngeal closure may be a result of an unusually deep nasopharynx, poor lateral wall and palate mobility (which may be due to enlarged tonsils, or a structural insufficiency of the soft palate), or the lateral or posterior pharyngeal walls. ${ }^{5}$ So, the treatment of VPI is directed at these causative factors. Over the years, the treatment for VPI has been either a sphincter pharyngoplasty or pharyngeal flap. ${ }^{6}$ These procedures aimed at the correction of the lateral or posterior pharyngeal wall movements, thereby decreasing the diameter of the velopharyngeal port; however, in cases of a short palate, it did not address the length of the palate as such. The large number of techniques available perhaps best reflects that no one technique is ideal and that each patient may have one or more factors resulting in their velopharyngeal incompetence. In a clinical setting, the decision as to which factor is responsible for the VPI is confirmed by an objective speech assessment, a videofluoroscopy, or nasopharyngoscopy. A nasopharyngoscopy is being avoided in young patients with less tolerance to the procedure. We hereby present a case report of a patient that had presented with VPI and was operated with the MM flap.

\section{CASE REPORT}

A 6-year-old patient was brought to the maxillofacial outpatient department by his parents who complained that the patient had difficulty in pronouncing certain words and spoke with a distinct nasal twang. On examination, the patient had a scar on his upper lip on the left side extending throughout the length from the height of the Cupid's bow on the left side to the left nostril sill, suggesting a previous surgery to repair a left unilateral cleft lip (Fig. 1). The nostrils were asymmetrical and the nose tip had a slight deviation to the right. On intraoral examination, a scar was noted at the midline of the hard palate suggestive of a previous surgery to repair a cleft palate (Fig. 2). The palate length was found to be short by objective speech assessment. A videofluoroscopy or a nasopharyngoscopy was not deemed necessary to rule out VPI due to other factors because of the clinically apparent nasal emission that gave a clear indication that the short palate length was the primary factor. The treatment that was planned was a bilateral buccinator myomucosal flap for palate lengthening. The technique is outlined 


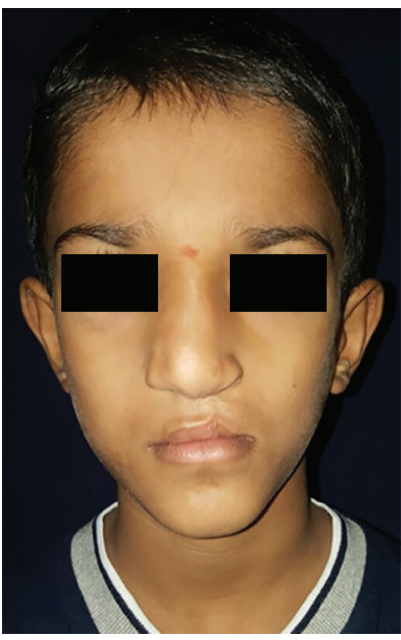

Fig. 1: Clinical photograph

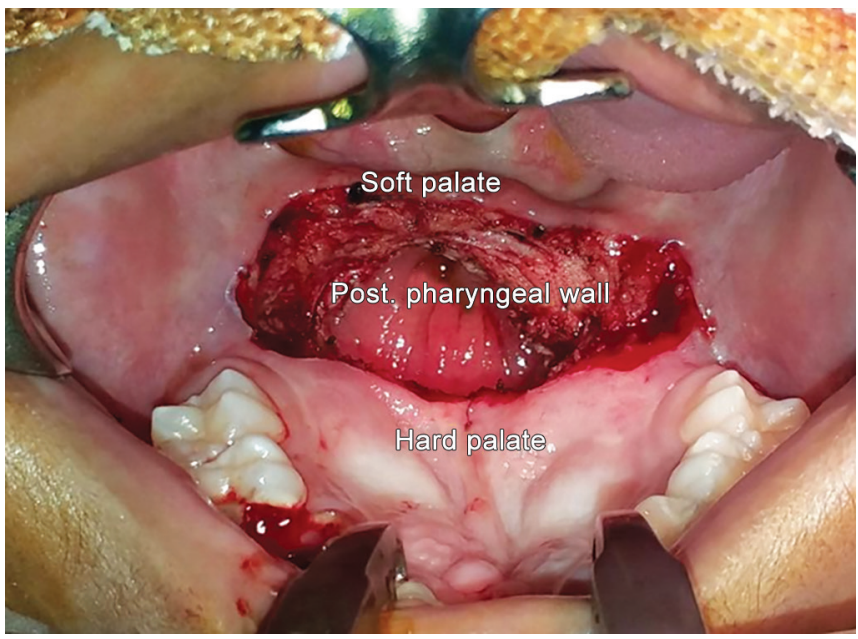

Fig. 3: Division of the hard/soft palate junction. Note that the soft palate drops posteroinferiorly, creating the defect

as follows. The junction of the hard and soft palates is first marked and divided, detaching the soft palate and allowing it to move toward the posterior pharyngeal wall, creating the defect that will be reconstructed using bilateral buccinator flaps (Fig. 3). This flap is a random pattern flap based near the anterior pillar of the fauces. The flap is planned in the mid-part of the cheek, below the parotid papilla, adhering to a 2:1 width to length dimension; it is raised in an anteroposterior direction, including thickness of the buccinator muscle (Fig. 4). The flap can be islanded on a pedicle of buccinator muscle. The first flap raised is sutured mucosal surface upward into the nasal layer of the defect (Fig. 5); the opposite flap is then raised and sutured mucosal surface down into the oral layer of the defect (Figs 6 and 7). The donor sites on either cheek are closed directly with attention being paid to repair of the defect in the remaining buccinator muscle (Fig. 8). All patients are restricted to a strict fluid diet for a week after the surgery and are discharged when comfortable and able to manage adequate oral intake.

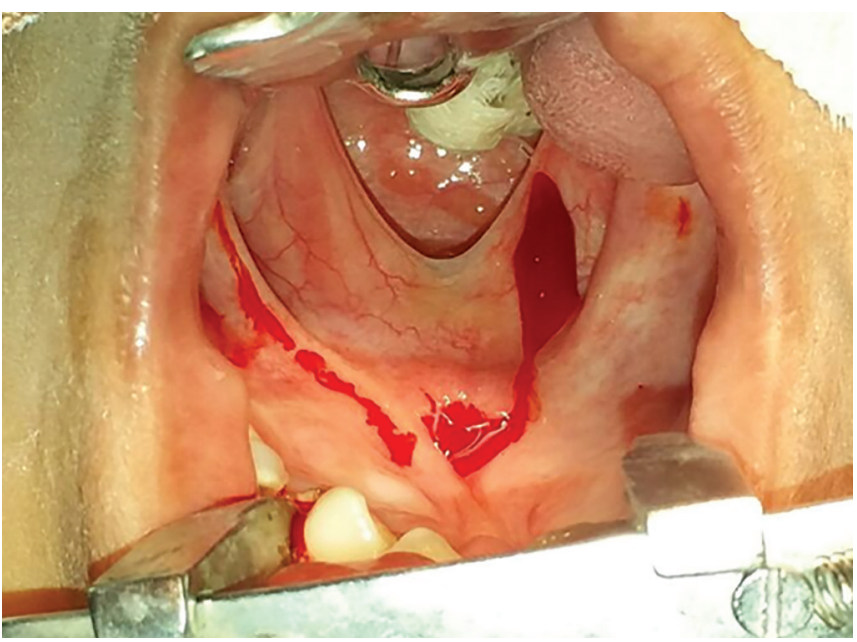

Fig. 2: Preoperative photograph showing short palate length

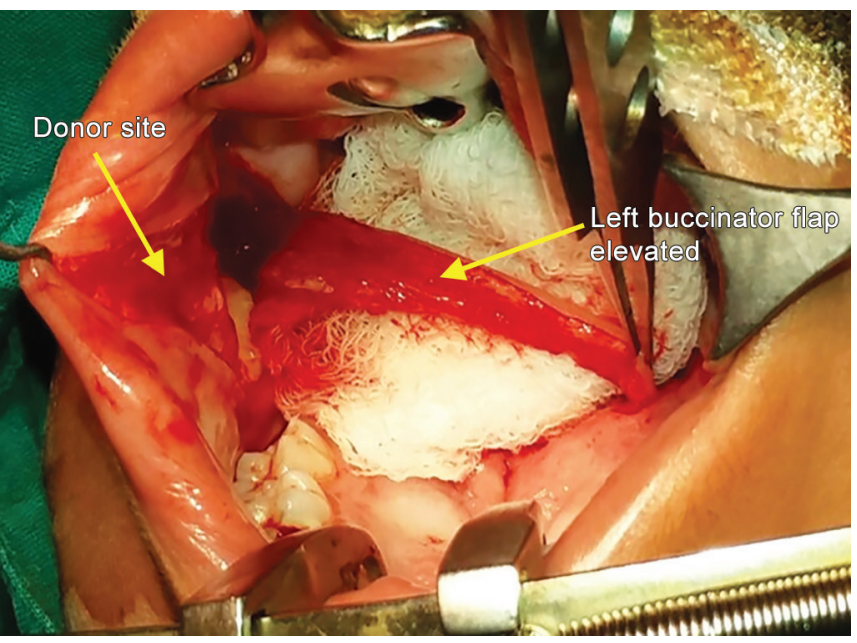

Fig. 4: Left buccinator flap elevated

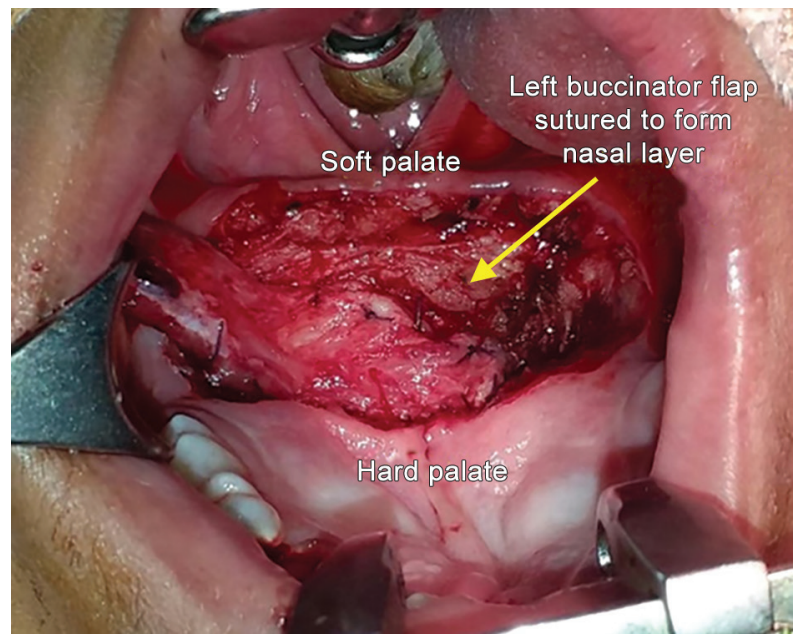

Fig. 5: Left buccinator flap with the anterior edge sutured. The mucosal surface faces superiorly to reconstruct the nasal layer defect

\section{DISCUSSION}

Palate lengthening for the correction of velopharyngeal incompetence has a long history. The buccal mucosal flap 


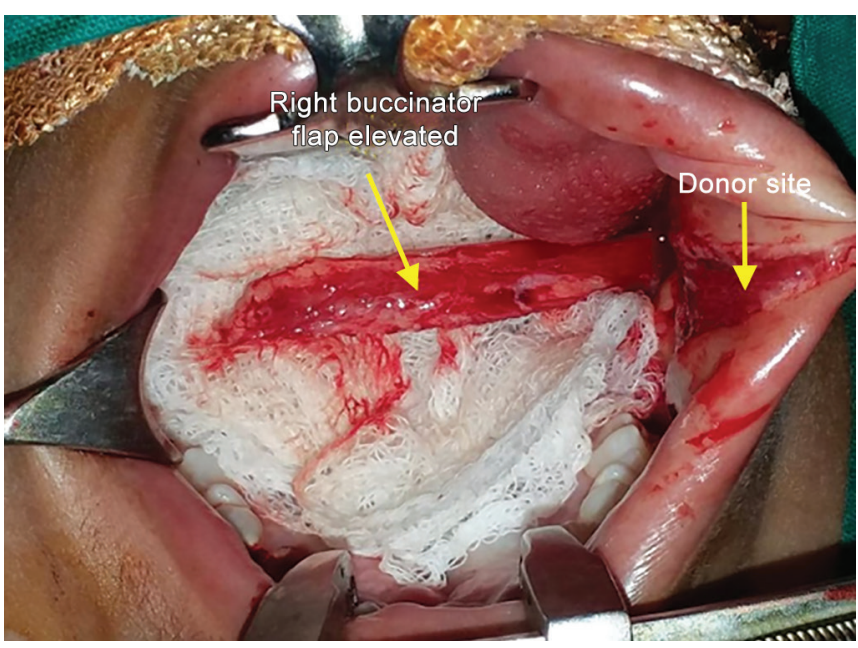

Fig. 6: Right buccinator flap elevated

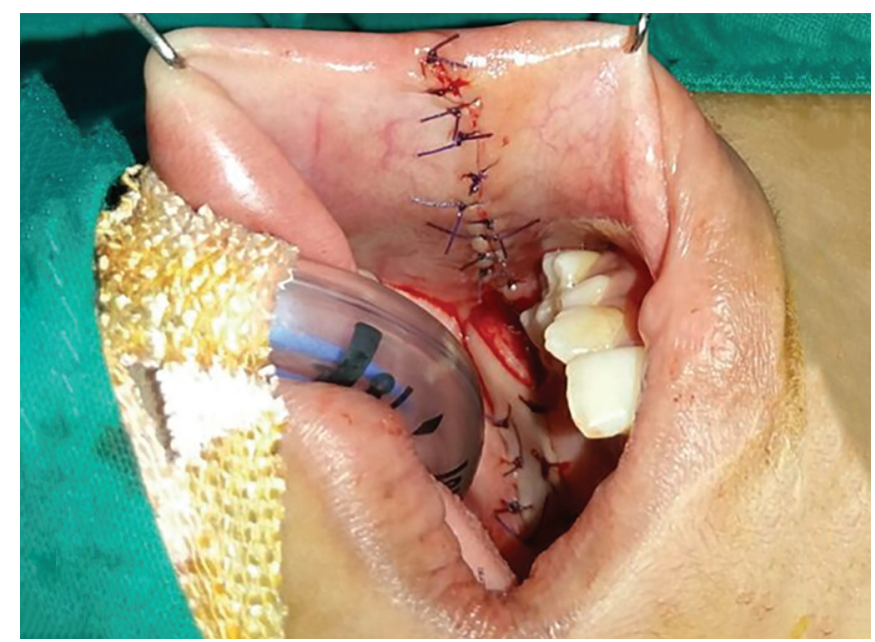

Fig. 8: Primary closure of the donor site

was described as early as the 1930s by Padgett, ${ }^{7}$ who used the flap in salvage procedures as well as for the raw nasal layer in a Dorrance-type pushback. Blair has been cited by Padgett and others as having described the flap for similar use as early as 1922. Pushback operations were reported as early as the 1800s, but were championed by Dorrance, ${ }^{8}$ who first reported his technique in 1925. He described an anterior incision with elevation of the mucoperiosteum of the hard palate and division of the palatine aponeurosis to allow posterior displacement of the hard and soft palate. He reported a gain in length of "one-half to three quarters of an inch." His technique was widely adopted. Its effectiveness was limited by the tethering effect of the palatine vessels and by the raw nasal surface with resultant healing by secondary intention and contracture. As a result of these drawbacks, the technique was subject to a number of subsequent modifications. Brown ${ }^{9}$ described dissection of the palatine vessels from their foramina as a means of obtaining increased length. This was extended further by Conway, ${ }_{1}^{10}$ who removed

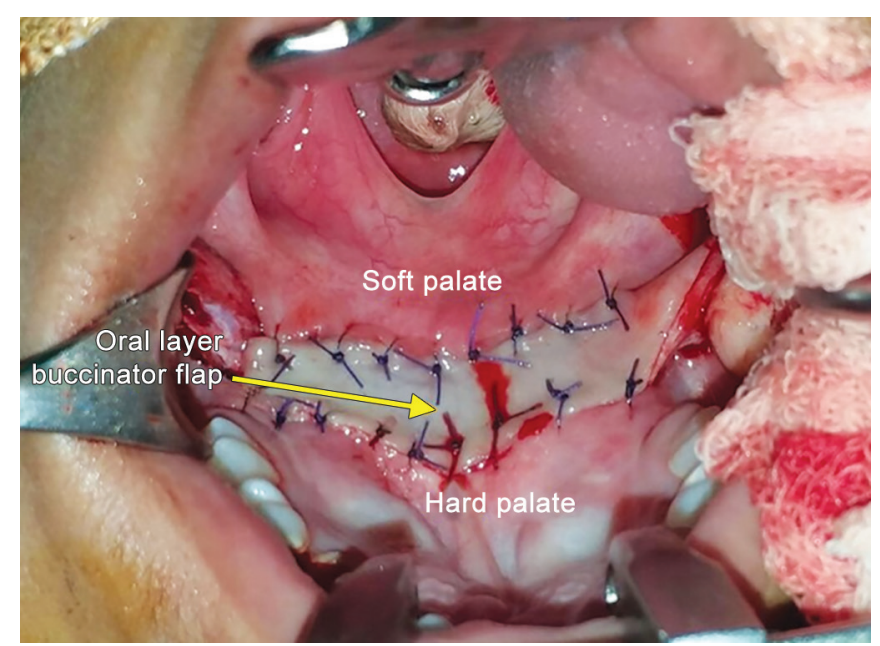

Fig. 7: Oral layer flap completely sutured in place prior to closure of the secondary defect on the right cheek

the posterior wall of the bony palatine canal to lengthen the vessel further. Conway also addressed the problem of the raw nasal surface using a pharyngeal flap for cover. Prior to this description, the raw nasal surface was either allowed to heal by secondary intention or grafted. Padgett ${ }^{7}$ described the use of a cheek flap for cover of the raw nasal surface. This was, in essence, a buccinator flap but prior to its anatomy being delineated or understood. Cronin ${ }^{11}$ elevated flaps from the nasal floor slid posteriorly, effectively moving the raw surface anteriorly onto the superior surface of the hard palate. Though the use of myomucosal buccinator flaps in cleft surgery was first described in 1969 for the primary repair of a wide cleft palate by Mukherji, ${ }^{12}$ it was Bozola et $\mathrm{al}^{13}$ who first formally described it and gave first description of its anatomy. The first report on the use of myomucosal buccinator flaps to lengthen the palate in secondary VPI was published by Hill et al. ${ }^{14}$ In this prospective study carried out between 1995 and 1998, a group of 16 patients with insufficient velopharyngeal closure were managed by bilateral buccinator myomucosal flaps. According to this study, $86 \%$ of the patients had normal resonance and no patients were hyponasal postoperatively. The audible nasal escape was also significantly improved by surgery. In 2008, Robertson et $\mathrm{a}^{15}$ described their experience with the addition of a single myomucosal buccinator flap to a palate re-repair in secondary cleft palate surgery in 20 patients with VPI or palatal fistulas. They reported a significant improvement in nasal resonance, nasal emission, and intelligibility, based on a chart review. However, their results are difficult to interpret because of the small number of patients, the absence of a blind, independent speech analysis, and the mixed indication of VPI and fistulas. Recently, Mann et $\mathrm{a} 1^{16}$ published their experience with using bilateral buccinator myomucosal flaps for VPI in a retrospective review of 27 patients. The 
authors described a postoperative improvement in both resonance and intelligibility. However, no blind independent speech analysis was performed, and they failed to report the nasal airflow errors of nasal air emission and nasal turbulence. In a retrospective study conducted by Hens et $\mathrm{al}_{1}^{17} 32$ consecutive patients underwent the buccinator flap procedure; in $81 \%$ of patients, speech outcome was such that no further velopharyngeal surgery was considered necessary at the time of follow-up. The buccinator flap procedure resulted in a mean palate lengthening of $7.5 \mathrm{~mm}$. After the operation, there was a complete elimination of the velopharyngeal gap on lateral videofluoroscopy in $77 \%$ of patients. It was also found that there were significant decreases in hypernasality ratings and passive cleft type articulation errors postoperatively.

\section{CONCLUSION}

The buccinator flap procedure is a relatively safe and easy procedure. It is an appropriate surgical option in patients in which short palate length is the primary factor in VPI.

\section{REFERENCES}

1. Grunwell P, Brondsted K, Henningsson G, Jansonius K, Karling J, Meijer M, Ording U, Wyatt R, Vermeij-Zieverink E, Sell D. A six-centre international study of the outcome of treatment in patients with clefts of the lip and palate: the results of a cross-linguistic investigation of cleft palate speech. Scand J Plast Reconstr Surg Hand Surg 2000 Sep;34(3):219-229.

2. Sell D, Harding A, Grunwell P. GOS.SP.ASS.'98: an assessment for speech disorders associated with cleft palate and/ or velopharyngeal dysfunction (revised). Int J Lang Commun Disord 1999 Jan-Mar;34(1):17-33.

3. Harding A, Grunwell P. Active versus passive cleft-type speech characteristics. Int J Lang Commun Disord 1998 JulSep;33(3):329-352.
4. Rudnick EF, Sie KC. Velopharyngeal insufficiency: current concepts in diagnosis and management. Curr Opin Otolaryngol Head Neck Surg 2008 Dec;16(6):530-535.

5. Yules RB. Secondary correction of velopharyngeal incompetence. Plast Reconstr Surg 1970 Mar;45(3):234-246.

6. Sloan GM. Posterior pharyngeal flap and sphincter pharyngoplasty: the state of the art. Cleft Palate Craniofac J 2000 Mar;37(2):112-122.

7. Padgett EC. The repair of cleft palates primarily unsuccessfully operated upon. Surg Gynecol Obstet 1936;63:483-496.

8. Dorrance GM. Lengthening the soft palate in cleft palate operations. Ann Surg 1925 Aug;82(2):208-211.

9. Brown JB. Double elongations of partially cleft palates and elongations of palates with complete clefts. Surg Gynecol Obstet 1940;70:815-818.

10. Conway H. Combined use of the push-back and pharyngeal flap procedures in the management of complicated cases of cleft palate. Plast Reconstr Surg 1951 Mar;7(3):214-224.

11. Cronin TD. Method of preventing raw area on nasal surface of soft palate in push-back surgery. Plast Reconstr Surg 1957 Dec;20(6):474-484.

12. Mukherji MM. Cheek flap for short palates. Cleft Palate J 1969 Oct; $6: 415-420$.

13. Bozola AR, Gasques JA, Carriquiry CE, Cardoso de Oliveira M. The buccinator musculomucosal flap: anatomic study and clinical application. Plast Reconstr Surg 1989 Aug;84(2): 250-257.

14. Hill C, Riaz M, Leonard AG. A technique for repair of the 'unrepairable' cleft palate. Br J Plast Surg 1999 Dec;52:658-660.

15. Robertson AG, McKeown DJ, Bello-Rojas G, Chang YJ, Rogers A, Beal BJ, Blake M, Jackson IT. Use of buccal myomucosal flap in secondary cleft palate repair. Plast Reconstr Surg 2008 Sep;122(3):910-917.

16. Mann RJ, Neaman KC, Armstrong SD, Ebner B, Bajnrauh R, Naum S. The double-opposing buccal flap procedure for palatal lengthening. Plast Reconstr Surg 2011 Jun;127(6): 2413-2418.

17. Hens G, Sell D, Pinkstone M, Birch MJ, Hay N, Sommerlad BC, Kangesu L. Palate lengthening by buccinator myomucosal flaps for velopharyngeal insufficiency. Cleft Palate Craniofac J 2013 Sept;50(5):e84-e91. 